\title{
Application of ZigBee and Speech Recognition in Intelligent Home System
}

\author{
Chen Hong ${ }^{1, a^{*}}$ \\ ${ }^{1}$ School of computer science, Wuhan Donghu University, Wuhan, HuBei,430212 China \\ a30315495@qq.com
}

Keywords: Intelligent home; ZigBee; speech recognition; Remote control

\begin{abstract}
This paper puts forward a framework of intelligent home system based on ZigBee technology and speech recognition technology, the ZigBee nodes in the system are connected by network topological form of mesh network, in which CC2530 chip uses the ZigBee PRO/2007 protocol stack provided by TI to design the software, The communication distance index of CC2530 Communication node module is emphatically tested.
\end{abstract}

\section{Introduction}

With the rapid development of IoT technology in China in recent years, intelligent home as an important application of IoT technology has become a research hotspot. With the level of science and technology and the improvement of the quality of life, people have put forward higher requirements for living and working environment. Intelligent home is gradually to energy-saving, environmental protection, integration, intelligence, networking, standardization, the direction of human development. This paper presents and designs a solution of intelligent home system based on ZigBee wireless communication technology and \$literal speech recognition technology. The system uses the CC2530 chip to design the ZigBee network communication node, uses the combustible gas, the temperature humidity, the raindrop and so on many kinds of sensors to realize the home intelligent security and the indoor, the outside environment monitoring. The speech recognition function and the ZigBee technology are integrated, and the Voice control of home appliance and equipment is realized through speech recognition.

\section{ZigBee Equipment and network topology}

The ZIGBEE network supports the network topologies with star-shaped, tree-shaped and mesh networks. In the three network topologies of ZigBee, it can be seen that in a star-shaped network, there is no communication between the child nodes, they can only communicate with the coordinator node. In a mesh network, routers and coordinators can communicate with each other and have routing capabilities, and terminal nodes can only communicate with their parent nodes. ZigBee Three kinds of network topologies are shown in 1.

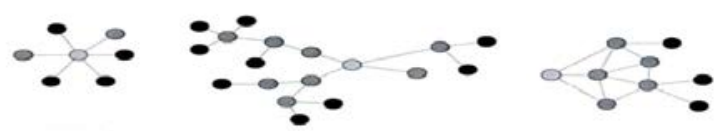

star-shaped network tree-shaped network mesh network

$\bigcirc$ coordinator $\bigcirc$ router $\bullet$ terminal node

Each device in a ZigBee network has its globally unique 216-bit 1EEE address, and has a relatively unique pan network identifier. There can be several different ZigBee networks in the same space, with different pan identifiers. When the coordinator device establishes the network, the terminal equipment and the router device join the network and assign them a 24-bit short address, so that the device can be point-to-point unicast or One-to-many broadcast communication between the short address or the IEEE address. A ZigBee network theory supports 65,536 network nodes, and chooses mesh network form in network topological structure. 


\section{Design of ZigBee Wireless communication module}

With the development of ZigBee technology, the world's major semiconductor manufacturers have launched a support EEE802. 15.4 Standard wireless transceiver chip. The more mature RF chip used for ZigBee communication in the market is mainly CC2430 and CC2530 chips produced by Texas Instruments Company. The CC2530 chip is a chip designed to optimize and upgrade on the basis of CC2430 chip, which is used to realize embedded ZigBee application. The chip pins are shown in Figure 2.

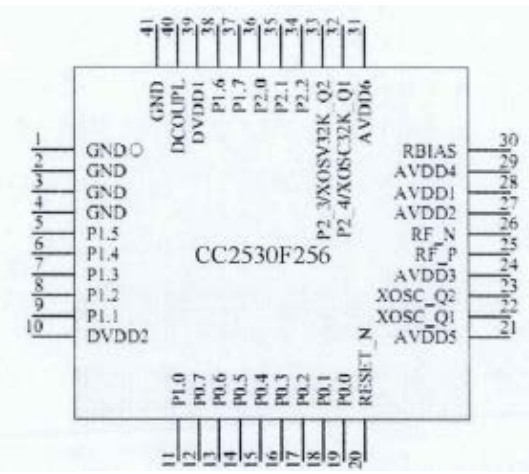

Fig. 2 CC2530 chip Pins

The CC2530 chip incorporates a single cycle of 8051 cores in which the broken controller provides 18 interrupt sources, which can wake up the sleep device through some interrupts. Programmable flash memory blocks provide nonvolatile program memory, in addition to saving code, variables, but also to save data such as network configuration, which is of great significance in the specific application. CC2530 Communication module circuit schematic design as shown in Fig. 3, the circuit design will be CC2530 communication module in the CC2530 chip pin all lead, the module of the power supply circuit, debug interface and keys, LED indicators and other peripherals are all through the PIN to the corresponding module on the floor.

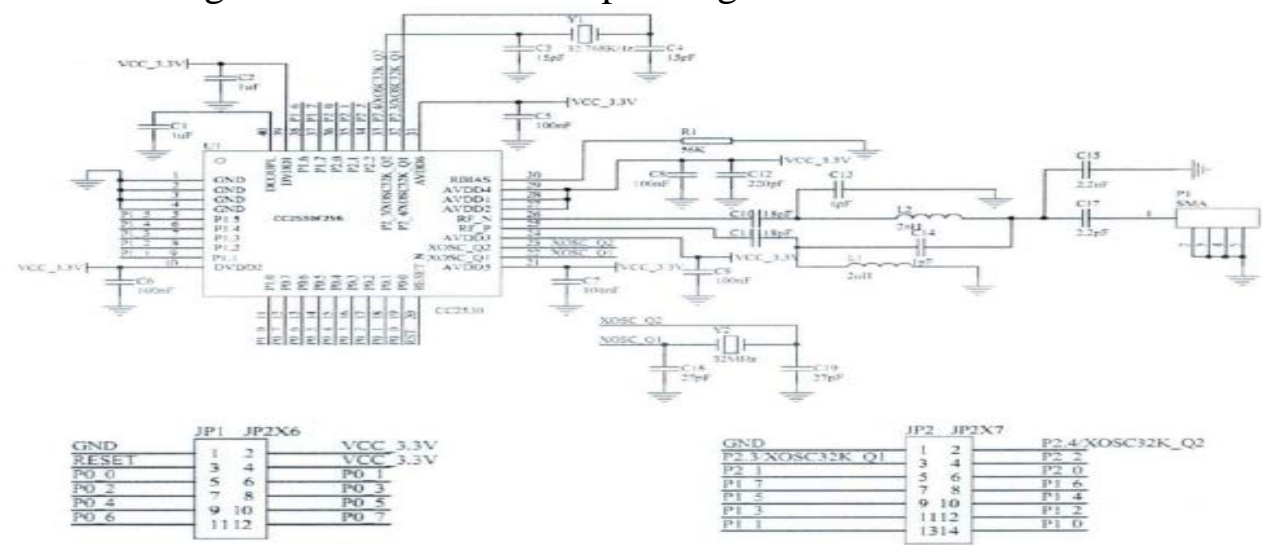

Fig. 3 schematic diagram of CC2530 pass-times module

For the selection of the capacitance $(\mathrm{C} 18, \mathrm{C} 19)$ of the $32 \mathrm{MHz}$ crystal oscillator connected to the XTALI pin, you can refer to the following formula (Cparasitic the parasitic capacitance generated for the wiring structure):

$$
C_{L}=\frac{1}{\frac{1}{C_{18}}+\frac{1}{C_{19}}}+C_{\text {parasitic }}
$$

For the XTAL2 pins connected to the clock crystal oscillator. 768kh/Crystal Oscillator, the selection of its load capacitance (C3, C4) is given by the formula below (cparasitic for the parasitic capacitance generated by the wiring structure):

$$
C_{L}=\frac{1}{\frac{1}{C_{3}}+\frac{1}{C_{4}}}+C_{\text {parasitic }}
$$




\section{Application of ZigBee and speech recognition in intelligent home system}

The testing of the intelligent home system includes the individual tuning and testing of each component hardware and software of the system, and after the completion of the step, the whole system is debugged on-line, and the problems of hardware and software in the system are optimized and improved. The design of the intelligent Home System Network Transmission technology utilizes ZigBee wireless communication network, the ZigBee nodes in the system adopt the CC2530 communication module, so the performance of CC2530 wireless communication module plays an important role in the performance of the system. The test of CC2530 communication module mainly includes the communication distance between nodes and packet loss rate, which can be used to evaluate the performance of CC253 () communication module. After setting up the hardware test environment, using the CC2530 program to download the emulator will be developed under the IAREmbedded Workbench integrated development Environment CC2530 serial communication program, and respectively download to CC2530 Coordinator and CC2530 router. The communication distance of CC2530 communication module are tested under different transmitting power and the performance of packet loss rate.

Table 1 CC2530 Communication module test in open spaces

\begin{tabular}{|c|c|c|c|c|}
\hline Group & $\begin{array}{c}\text { Transmitter } \\
\text { power setting } \\
(\mathrm{dBm})\end{array}$ & $\begin{array}{c}\text { Send Rate } \\
(\mathrm{ms})\end{array}$ & $\begin{array}{c}\text { Communication } \\
\text { distance }(\mathrm{m})\end{array}$ & $\begin{array}{c}\text { Packet loss } \\
\text { rate (\%) }\end{array}$ \\
\hline \multirow{2}{*}{$\begin{array}{c}\text { First } \\
\text { Group }\end{array}$} & -3 & 250 & 120 & 0.0 \\
\cline { 2 - 5 } & 1 & 250 & 120 & 0.0 \\
\hline \multirow{2}{*}{$\begin{array}{c}\text { Second } \\
\text { Group }\end{array}$} & 4.5 & 250 & 120 & 0.0 \\
\cline { 2 - 5 } & -3 & 250 & 130 & 11.6 \\
\hline \multirow{2}{*}{$\begin{array}{c}\text { Third } \\
\text { Group }\end{array}$} & 1 & 250 & 130 & 1.4 \\
\cline { 2 - 5 } & 4.5 & 250 & 130 & 0.0 \\
\cline { 2 - 5 } & -3 & 250 & 140 & 74.6 \\
\hline
\end{tabular}

Table 2 CC2530 Communication module test in indoor situation

\begin{tabular}{|c|c|c|c|c|}
\hline Group & $\begin{array}{c}\text { Transmitter } \\
\text { power setting } \\
(\mathrm{dBm})\end{array}$ & Send rate(ms) & $\begin{array}{c}\text { Communication } \\
\text { distance (m) }\end{array}$ & $\begin{array}{c}\text { Packet loss } \\
\text { rate (\%) }\end{array}$ \\
\hline \multirow{2}{*}{$\begin{array}{c}\text { First } \\
\text { Group }\end{array}$} & -3 & 250 & 20 & 0.0 \\
\cline { 2 - 5 } & 1 & 250 & 20 & 0.0 \\
\hline \multirow{2}{*}{$\begin{array}{c}\text { Second } \\
\text { Group }\end{array}$} & 4.5 & 250 & 20 & 0.0 \\
\cline { 2 - 5 } & -3 & 250 & 25 & 1.6 \\
\hline \multirow{2}{*}{$\begin{array}{c}\text { Third } \\
\text { Group }\end{array}$} & 1 & 250 & 25 & 0.0 \\
\cline { 2 - 5 } & 4.5 & 250 & 25 & 0.0 \\
\cline { 2 - 5 } & -3 & 250 & 30 & 12.0 \\
\hline \multirow{2}{*}{} & 4.5 & 250 & 30 & 2.3 \\
\hline
\end{tabular}

The transmitting frequency is $2.4 \mathrm{GHz}$ frequency band, and the $\mathrm{S}$ is 11 th channel, the transmitting power is respectively set as $-3 \mathrm{dBm}(0.5 \mathrm{~mW})$, $\mathrm{LdBm}(1.26 \mathrm{~mW})$ and $4.5 \mathrm{dBm}(2.82 \mathrm{~mW})$, and send and receive packets with a length of 22 hexadecimal data, A point-to-point communication between the coordinator and the router sends 1000 packets. Test results in the open environment are shown in table 1, as shown in table 2 in the general indoor environment. Communication distance of about $120 \mathrm{~m}$ packet loss rate is basically 0 , in indoor occasions using the default power output, communication distance of 25 meters, suitable for general home with obstacles in the environment to communicate. 
Table 3 Hardware node Name table

\begin{tabular}{|c|c|c|c|c|c|}
\hline & 1 & 2 & 3 & 4 & 5 \\
\hline 1 & $\begin{array}{l}\text { Air temperature } \\
\text { and humidity } \\
\text { sensor node }\end{array}$ & $\begin{array}{l}\text { Soil temperature and } \\
\text { humidity sensor node }\end{array}$ & $\begin{array}{l}\text { Air Quality } \\
\text { sensor node }\end{array}$ & $\begin{array}{l}\text { Rain Sensor } \\
\text { node }\end{array}$ & $\begin{array}{l}\text { Light intensity } \\
\text { Sensor node }\end{array}$ \\
\hline 2 & $\begin{array}{l}\text { Gas Solenoid } \\
\text { valve Node }\end{array}$ & $\begin{array}{l}\text { Shower Solenoid } \\
\text { valve Node }\end{array}$ & $\begin{array}{l}\text { Rain Hitch } \\
\text { Node }\end{array}$ & Fan node & $\begin{array}{lr}\begin{array}{l}\text { Drop } \\
\text { Solenoid } \\
\text { node }\end{array} & \text { Canister } \\
\end{array}$ \\
\hline 3 & $\begin{array}{l}\text { Smoke } \\
\text { detection Node }\end{array}$ & $\begin{array}{l}\text { Gate Magnetic } \\
\text { Detection Node }\end{array}$ & $\begin{array}{l}\text { Lighting } \\
\text { Switch Node }\end{array}$ & $\begin{array}{l}\text { Humidifier } \\
\text { Node }\end{array}$ & Fish Feeder Node \\
\hline 4 & $\begin{array}{c}\text { Combustible } \\
\text { Gas exploration } \\
\text { node }\end{array}$ & $\begin{array}{l}\text { Infrared pyroelectric } \\
\text { Detection Node }\end{array}$ & $\begin{array}{l}\text { Glass Broken } \\
\text { Detection } \\
\text { Node }\end{array}$ & $\begin{array}{l}\text { Audio-Learning } \\
\text { Infrared node }\end{array}$ & $\begin{array}{l}\text { Air-conditioning-L } \\
\text { earning infrared } \\
\text { node }\end{array}$ \\
\hline 5 & - & Voice Control node & $\begin{array}{l}\text { Key Remote } \\
\text { Control node }\end{array}$ & - & SIM300 node \\
\hline
\end{tabular}

According to the function of intelligent Home system, the testing of intelligent home system mainly includes the following aspects: triggering the alarm node by the artificial external condition or the test key, respectively, the Smoke detection node, the glass crushing node, the gate magnetic node, the gas detection node and the infrared detection node. Fire solenoid valve node or gas solenoid Valve node action and alarm short message sent, camera monitoring photos of the test, to trigger the Raindrop detection node, air quality detection node, air temperature Humidity detection node through the artificial external conditions or test keys, flowerpot Soil Moisture detection node, light intensity detection node, Infrared detection node, etc. to start the rain-Lap device node, fan node, humidifier node, dehumidifier node, drip control solenoid valve node, curtain control node, lighting control node and other node action test; Through the key remote control node to achieve the lighting, curtains, LCD TVs, air-conditioning, drip-irrigation solenoid valve, such as home appliances equipment remote controlled testing; Through the Voice recognition node to achieve the lighting, curtains, audio equipment, LCD TV and other voice control of the opening, turn-off function test; through the mobile phone short message, remote control testing on the Rain-lapping device, air-conditioning, electric water heaters, air-conditioning fan, lighting, drip irrigation solenoid valve, fish feeder.

\section{Conclusion}

Intelligent security applications smoke sensor, gas sensor, door magnetic detection, infrared detection, glass fragmentation detection and other sensors, detectors and ZigBee technology, designed based on CC2530 RF chip Intelligent security sensor detection node; will be used for indoor and outdoor environment monitoring of raindrops, air temperature and humidity, soil temperature and humidity, With the combination of light intensity sensor and ZigBee technology, the sensor detection node of intelligent home appliance based on CC2530 is designed. Through the CC2530 chip control fire solenoid valve, alarm, gas solenoid valve and so on designed intelligent security Actuator node; Through CC2530 chip control Rain-lapping device, fan, humidifier, dehumidifier, drip electromagnetic valve, curtains, fish feeder, lighting, etc. design Intelligent appliance Actuator node. For audio, air conditioning, LCD TV control design based on CC2530 Learning infrared node.

\section{Acknowledgements}

This paper is supported by Youth Foundation of Wuhan Donghu University.

\section{References}

[1] Zhao Feixiang, Zhang Yuan, Zhang Yanjun, Zhang Peiwen, Wang Mingyu. Intelligent Home 
System based on ZigBee remote speech control [J]. Computer knowledge and technology, 2017, (04): 189-190.

[2] Jiang Tai, Zhang Linjun. Application of adaptive Speech recognition algorithm in intelligent home [J]. Computer systems applications, 2017, (03): 150-155.

[3] Yang Xi, Zhang Wenzhao, Liang Xiolin. Application of speech recognition in intelligent home control system [J]. Journal of Hunan University of Science and Technology, 2016, (10): 34-35.

[4] Guo Lili. The application of ARM speech recognition controller in intelligent Home [J]. Silicon Valley, 2015, (02): 264-265.

[5] WangAiyun. Application of speech recognition technology in intelligent Home[J]. Software, 2015, (07): 104-107. 